\title{
The Relationship of Social Network and Employment to People's Life Satisfaction - Based on the Empirical Analysis of OECD Countries
}

\author{
Yuanzhao Zhang \\ Fujian Academy of Social Sciences \\ Fuzhou, China 350001
}

\begin{abstract}
With economic development and social progress, people's life satisfaction has become the focus of economists. Based on the Better life index data of OECD countries from 2013 to 2016, this paper analyzes the impact of social network, employment rate and other macroeconomic factors influencing people's life satisfaction. The results show that both social network and employment rate have a significant impact on people's life satisfaction in OECD countries, and the expansion of social network and the increase of employment rate will improve people's life satisfaction level. The study also finds that family income had little effect on life satisfaction in developed countries such as the OECD. At the same time, this paper also puts forward some suggestions to improve people's life satisfaction in China.
\end{abstract}

Keywords-social network; employment rate; life satisfaction; OECD

\section{INTRODUCTION}

With the continuous development and progress of the economy and society, welfare economics has developed rapidly, and the economic growth that is "GDP"-oriented has been opposed by more and more economists. Some scholars and institutions have proposed many alternative and supplementary indicators of "GDP", such as Human development index (UNDP, 1990) and OECD Better life index (OECD, 2011). The emergence of these indicators to measure people's quality of life indicates that economic growth is no longer the sole goal of social development. The indicator of people's life satisfaction can reflect people's cognition and evaluation of the current living state stably, and can better reflect the social development than the GDP index alone, thus it has become the focus of economists' attention. The research of Verkuyten (2008) shows that under the control of individual characteristic variables, immigrants and residents in minority areas tend to have lower life satisfaction in a country. On the one hand, immigrants often have language and communication barriers, and it's difficult for them to get help from neighbors or others when they encounter difficulties and troubles. On the other hand, some countries discriminate against immigrants and residents of ethnic minorities, which is also an important reason for the low life satisfaction of immigrants or ethnic minorities (Verkuyten, 2008; Bobowik et al., 2015). The research of OECD (2016) shows that unemployment rate, personal health status and circle of friends (social network) all have significant influence on life satisfaction.

According to neoclassical economic theory, people only choose to work when their income level exceeds a certain limit. And some recent research by sociologists suggests that people don't work for money. Jahoda et al. (2009) believed that not going to work would cut off the social connections between people, break people's normal daily life arrangements, and make them feel that they had nothing to contribute to the society. Layard (2011) found that employment is one of the three most critical factors affecting people's happiness or satisfaction, through which income can be obtained for consumption and the utility level of the whole society can be improved. Knabe et al. (2010) used the method of experimental economics to conduct a long-term follow-up survey on 1000 employed and unemployed people respectively. Each person needed to record what they had done every day and write down their emotional changes. It was found that, people who were unemployed had lower life satisfaction than those who had jobs overall.

\section{DATA SOURCES AND EMPIRICAL METHODS}

\section{A. Data Sources}

The data used in this analysis are from the better life index published by OECD. The index includes material wealth (such as family income, work and housing) as well as indicators that can reflect people's quality of life, such as residents' health, education, living environment, employment and social connections. The data samples were from 2013 to 2016.

\section{B. Empirical Method}

The panel data model can overcome the multicollinearity among variables, and can effectively identify the influence factors that cannot be found by the simple time series model and the simple cross section data model, and solve the problem of missing variables in the model. Therefore in this paper the panel data model is used to analyze the impact of social network and employment rate on people's life satisfaction. The specific form and variables of the equation are explained as follows: 
LFS $_{i t}=\beta_{0}+\beta_{1}$ Network $_{i t}+\beta_{2}$ Employment $_{i t}+\beta_{3}$ Hincome $_{i t}+$

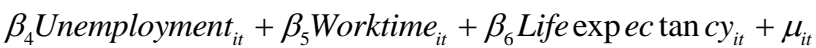

In this equation, LFS represents people's life satisfaction, which measures people's feeling and evaluation of the current quality of life. Its value is $0-10$, and the higher the value is, the higher the life satisfaction is.

- Network represents social Network, which is a theoretical construction of social science to describe the social relationship among people. However, there is no consensus on its definition and measurement in academia (Lin and Peek, 1999). In the study of life satisfaction, the researcher define social network as a social phenomenon composed of entities connected by various relationships. These relationships include friendship, kinship, discussion network, neighborhood interactions, and social engagement, reflecting human interaction and interconnectedness (Carpenter, et al. A1, 2012). In this article, social network is measured by the percentage of people who can get help from relatives, friends, neighbors, etc., when they are in trouble.

- Employment represents Employment rate, which refers to the proportion of people aged between 15 and 64 who are currently employed in OECD countries. It is also the most commonly used indicator to study factors affecting life satisfaction.

- Hincome represents household disposable income, which includes people's income from work, inheritance and social transfer payment, etc. In some literatures, researchers believe that the amount of family wealth will significantly affect residents' life satisfaction.

- Unemployment stands for Unemployment rate, referring to the percentage of the workforce not employed for a year or more.

- Work time represents the working conditions, which refers to the proportion of the employed people who work more than 50 hours a week. It measures the long working hours of the workers and can reflect the working conditions of the workers.

- Life expectancy stands for life expectancy, which measures the average life expectancy of people at birth in OECD countries.

\section{EMPIRICAL RESULTS}

\section{A. Descriptive Statistics of Variables}

According to the data of OECD Better life index in 2016, people's life satisfaction varies greatly among different countries. People in Portugal, Hungary, Turkey and other countries have relatively low life satisfaction, with a life satisfaction level of about 5.5 or below. At the other end of the scale, countries such as Norway and Switzerland reported life satisfaction levels as high as 7.6 (see "Fig. 1").

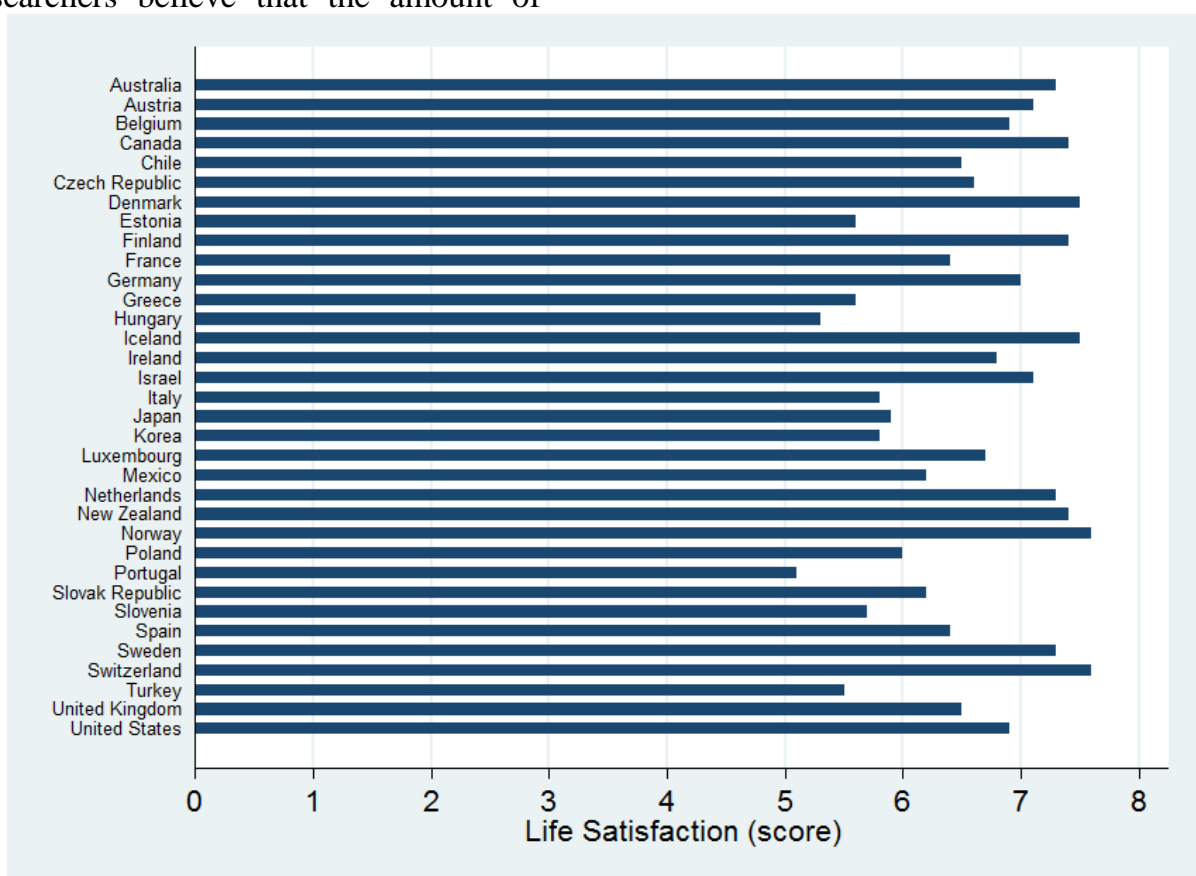

Fig. 1. People's life satisfaction of people in OECD countries in 2016 (Data sources: OECD. Stat).

Secondly, as can be seen from the data, there is a high correlation between social network and people's life satisfaction. People with better social network tend to have higher life satisfaction, such as Norway and New Zealand. 
Hungary and South Korea, which have poor social network, also have low life satisfaction (see "Fig. 2" below). At the same time, a similar change can be seen in the relationship between employment rate and people's life satisfaction. Countries with high employment rate, such as Switzerland and Iceland, tend to have high life satisfaction of people, while countries with low employment rate, (see "Fig. 3" below) such as Turkey and Greece, tend to have low life satisfaction of people.

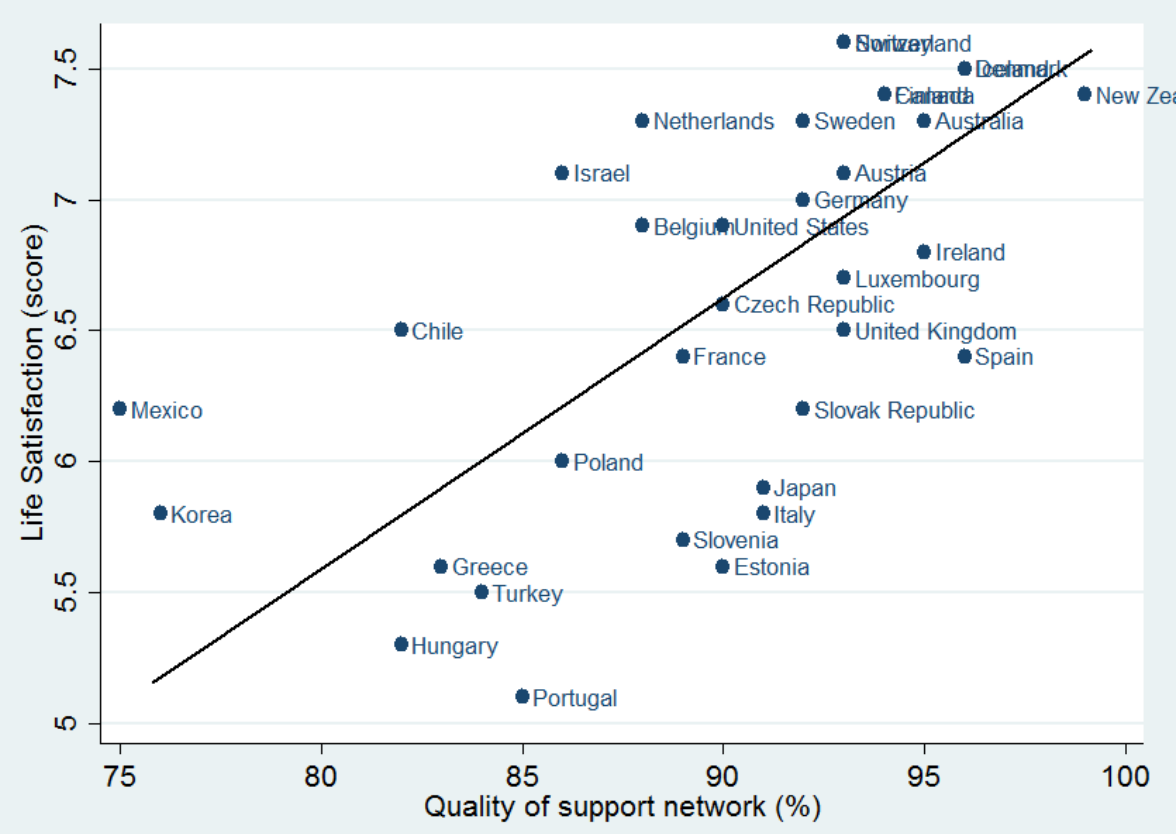

Fig. 2. People's life satisfaction and social network in OECD countries in 2016 (Data sources: OECD. Stat).

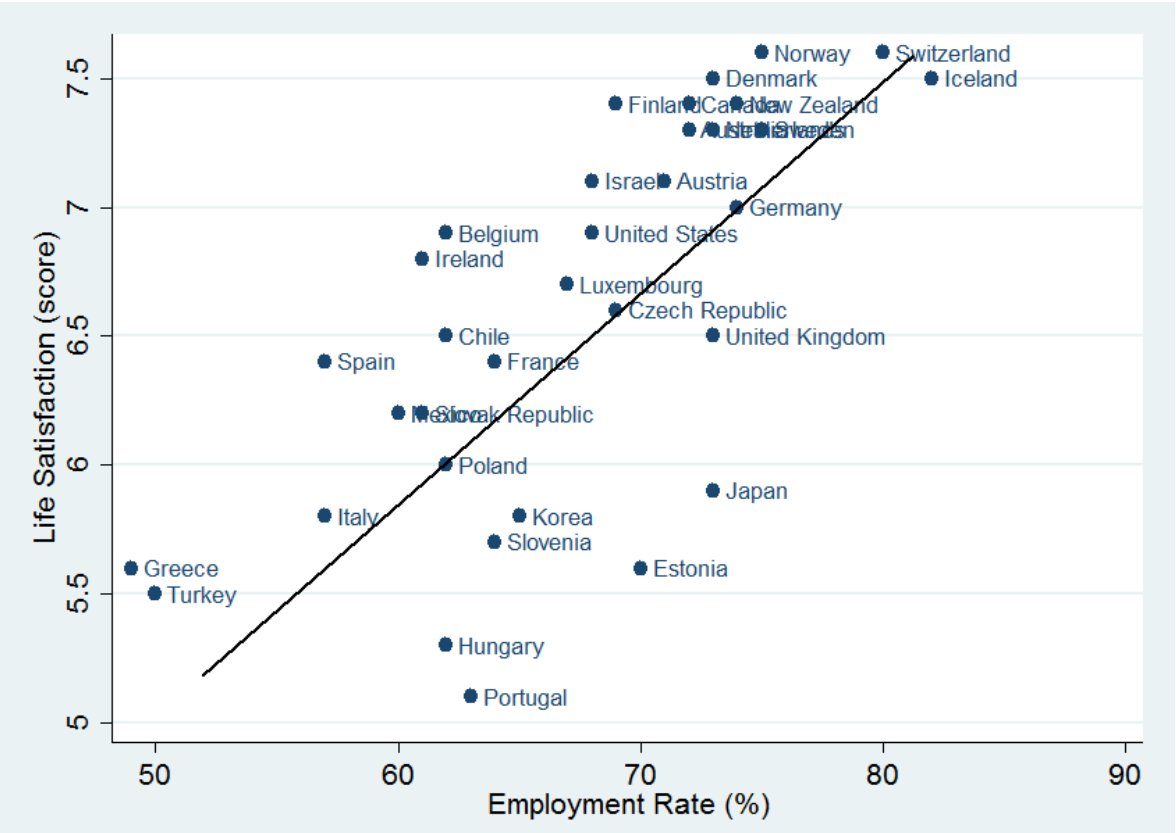

Fig. 3. People's life satisfaction and employment rate of people in OECD countries in 2016 (Data sources: OECD.Stat)

The descriptive statistics of each variable are shown in "Table I". From the perspective of descriptive statistics, there is a large gap between different indicators in OECD countries. In terms of life satisfaction, the lowest score is only 4.7, while the highest score is 7.8. There are also huge differences in social network. In some countries, people can almost always get help from friends and relatives when they are in trouble, the rate of which is as high as $99 \%$, whereas in some countries, it is only $68 \%$. 
TABLE I.

DESCRIPTIVE STATISTICS OF VARIABLES

\begin{tabular}{cllll}
\hline Variable & \multicolumn{1}{c}{ Mean } & Std. Dev. & Min & Max \\
\hline LFS & 6.60 & 0.82 & 4.7 & 7.8 \\
Network & 89.60 & 5.73 & 68 & 89 \\
Employment & 66.38 & 7.51 & 48 & 41355 \\
Hincome & 24073.98 & 6964.57 & 11039 & 19.47 \\
Unemployment & 3.42 & 3.50 & 0.01 & 46.13 \\
Worktime & 9.67 & 8.91 & 0.44 & 83.4 \\
Lifeexpectancy & 80.19 & 2.37 & 74.2 & a. Data source: OECD.Stat - Better life index data 2013-2016.
\end{tabular}

\section{B. Regression Results of the Equation}

Firstly, explanatory variables are put into the regression equation, and control variables are added into the equation in turn. According to the results of Hausman test, the fixed effect model should be adopted in this paper. The regression results are shown in "Table II" below:

TABLE II. RESULTS OF FIXED EFFECT REGRESSION EQUATION

\begin{tabular}{|c|c|c|c|c|c|}
\hline Variable name & Equation 1 & Equation 2 & Equation 3 & Equation 4 & Equation 5 \\
\hline Constant term & 3.16 & 2.11 & 2.93 & 1.97 & 1.3 \\
\hline Network & $0.02^{* * * *}$ & $0.019^{* * *}$ & $0.02^{* * *}$ & $0.02^{* * * *}$ & $0.019^{* *}$ \\
\hline Employment & $0.033^{* *}$ & $0.05^{* *}$ & $0.035^{* *}$ & $0.033^{* *}$ & $0.052^{* *}$ \\
\hline Hincome & $-0.0002^{*}$ & $-0.0002^{*}$ & $-0.0002^{*}$ & $-0.0002^{*}$ & $-0.0002^{*}$ \\
\hline Unemployment & & 0.029 & & & 0.029 \\
\hline Work time & & & 0.008 & & 0.010 \\
\hline Life expectancy & & & & 0.016 & 0.007 \\
\hline F-value & 31.85 & 28.43 & 30.68 & 31.42 & 27.9 \\
\hline Prob.(F-Statistic) & 0.00 & 0.00 & 0.00 & 0.00 & 0.00 \\
\hline
\end{tabular}

Note: $*$ represents the significance level of $10 \% ; * *$ represents the significance level of $5 \%$; and $* * *$ represents the significance level of $1 \%$

From the regression results, the model is relatively significant on the whole. From the regression results of the fixed-effect model, the social network has a positive impact on people's life satisfaction. When other variables remain unchanged, for every one percentage point of increase in social network, people's life satisfaction will increase by 0.02 units. It is easy to explain. In a society full of competition and cooperation today, everyone will meet with difficulties, and when people are in trouble, they naturally hope to get help from friends and family. So if people have a better social network, many things can be solved easily, the role of which to in promoting people's life satisfaction is obvious. At the same time, people can communicate their feelings in the process of participating in various social activities, provide help and share happiness, and thereby improve their own well-being (Putnam, 2000). Employment rate has a positive impact on people's life satisfaction. When other variables remain unchanged, for every percentage point of increase in employment rate, people's life satisfaction will increase by 0.05 units. From the perspective of reality, it is obvious that employment rate will affect people's life satisfaction, because a job is not only the source of family material wealth, but also an important carrier of people's social value. In this article, the OECD country's household income has little impact on life satisfaction, and even negative impact. People's life satisfaction did not increase with the increase of income. One possible reason is that OECD countries are mostly high-income countries, and people are pickier in the evaluation of life satisfaction. People with high income tend to face greater work pressure and may be more critical in the evaluation of life satisfaction.

\section{CONCLUSION}

Using the transnational panel data in the OECD better life index, this paper empirically analyzes the impact of social network, employment rate, family income and other macro factors on people's life satisfaction. In this study, it is found that the quality of social network and employment rate are important factors affecting people's life satisfaction Social network can provide people with instrumental help, emotional companionship, and help in negative life practices, which can help improve life satisfaction. The decline of employment rate will reduce people's life satisfaction. Unemployment means that individuals will be out of the society and lose the opportunity to realize social identity and self-value, which are potential factors affecting people's life satisfaction. At the same time, the study also found that the increase of family income did not significantly increase the life satisfaction of people in OECD countries. These research conclusions are also of great significance to developing countries like China. When economic development reaches a certain level, economic growth can no longer be taken as the key indicator to measure social progress. Instead, the humanoriented indicators should be paid attention to and the development of all aspects of society should be comprehensively coordinated, so as to ensure the continuous improvement of people's life satisfaction and the more harmonious and stable development of society. 


\section{REFERENCES}

[1] Richard A. Easterlina, Anke C. Plagnol. Life satisfaction and economic conditions in East and West Germany pre- and postunification $[\mathrm{J}]$. Journal of Economic Behavior \& Organization, 2008(68): 433-444. doi: 10.1016/j.jebo.2008.06.009

[2] Gundi Knies, Alita Nandi, Lucinda Platt. Life satisfaction, ethnicity and neighborhoods: Is there an effect of neighborhood ethnic composition on life satisfaction? [J]. Social Science Research, 60,110-124, doi.org/10.1016/j.ssresearch.2016.01.010

[3] Perović, L. M. Life satisfaction in Croatia. Croatian Economic Survey, 2010(12): 45-81.

[4] Frey, Bruno S. and Alois Stutzer. (2002) Happiness and Economics: How the Economy and Institutions Affect Human Well-Being [B]. Princeton, NJ: Princeton University Press.

[5] Xinyu (Jason) Cao. How does neighborhood design affect life satisfaction? Evidence from Twin Cities [J]. Travel Behaviour and Society, 2016(5): 68-76, doi.org/10.1016/j.tbs.2015.07.001

[6] Alex Coada, Martin Binder. Causal linkages between work and life satisfaction and their Determinants in a structural VAR approach [J]. Economics Letters, 2014(124): 263-268

[7] Rachel Margolis, Mikko Myrskyla. Family, money, and health: Regional differences in the determinants of life satisfaction over the life course [J]. Advances in Life Course Research, 2013(18): 115-126

[8] Frey, B. S. and A. Stutzer .What Can Economists Learn from Happiness Research? Journal of Economic Literature, 2002 (2): 402435.

[9] Dorota Celińska, Kornel Olszewski. The determinants of life satisfaction [J]. Ekonomia Journal, 2013, 34

[10] Frijters P, Haisken-Denew J P, Shields M A. Can the Large Swings in Russian Life Satisfaction be Explained by Ups and Downs in Real Incomes [J]. The Scandinavian Journal of Economics, 2006, 108(3): 433-458.

[11] Margolis R, Myrskylä M. Family, money, and health: regional differences in the determinants of life cycle life satisfaction [J]. Mpidr Working Papers, 2012, 18 (18).

[12] Verkuyten M. Life Satisfaction Among Ethnic Minorities: The Role of Discrimination and Group Identification [J]. Social Indicators Research, 2008, 89 (3): 391-404.

[13] Bobowik M, Basabe N, Páez D. The bright side of migration: hedonic, psychological, and social well-being in immigrants in Spain [J]. Social Science Research, 2015, 51: 189-204.

[14] Fowler J H, Christakis N A. Dynamic spread of happiness in a large social network: longitudinal analysis over 20 years in the Framingham Heart Study [J]. Bmj, 2008, 337(49): a2338-a2338. 